\title{
Recrystallization Kinetics and Microstructure Evolution of Annealed Cold-Drawn Low-Carbon Steel
}

\author{
Nurudeen A. Raji, Oluleke O. Oluwole
}

Department of Mechanical Engineering, University of Ibadan, Ibadan, Nigeria.

Email: kunle_raji@yahoo.com, lekeoluwole@gmail.com

Received July $23^{\text {rd }}, 2013$; revised August $23^{\text {rd }}, 2013$; accepted August $30^{\text {th }}, 2013$

Copyright (C) 2013 Nurudeen A. Raji, Oluleke O. Oluwole. This is an open access article distributed under the Creative Commons Attribution License, which permits unrestricted use, distribution, and reproduction in any medium, provided the original work is properly cited.

\begin{abstract}
The recrystallization behavior of cold-drawn $0.12 \mathrm{wt} \% \mathrm{C}$ steel during annealing at temperatures $600^{\circ} \mathrm{C}$ and $650^{\circ} \mathrm{C}$ was investigated. Hardness tests were used to characterize the recrystallization kinetics. The micrographs of the steel were obtained using optical microscopy $(\mathrm{OM})$ to characterize the grain microstructure of the non-treated and the annealed steel samples. Annihilation of dislocation defects occur within the soaking time of $5-10$ minutes for all the deformed steel after annealing at $650^{\circ} \mathrm{C}$. Specifically at 5 minutes soaking time the grains elongation is still observed indicating that reformation of grains is not taking place but recovery of the deformed grains. At the 10 minutes annealing time, new grains are observed to begin and full recrystallization is achieved at 15 minutes annealing time. At annealing time between 20 - 25 minutes, grains coarsening are observed indicating the onset of grain growth. The hardness of the material reduces with increasing annealing temperature for all the degree of cold drawn deformation. On the basis of the experimentally obtained hardness values, recrystallization increases with increasing degree of cold drawn deformation for the annealed steel. Recovery process was found to prolong in the $20 \%$ cold drawn steel as compared to the $55 \%$ cold drawn steel. The prolong recovery process is due to reduction in the driving force. Full recrystallization of the annealed steel is achieved at different soaking time depending on the degree of the cold drawn steel.
\end{abstract}

Keywords: Drawn Steel; Recovery; Recrystallization; Microstructure; Hardness; Soaking Time

\section{Introduction}

Drawn steel is products of metal drawing process which include bar or rod drawing, tube drawing and wire drawing. This drawing process has been widely used to manufacture fine wires, tension loaded structural components, springs, paper clips, spokes for wheels and plain nails $[1,2]$. The wire drawing process reduces the crosssection of a wire by pulling it through series of drawing dies of decreasing diameter to produce wires of desired diameters. It is mostly performed at room temperature and thus is classified as cold-work process. The original metal usually consists of strain-free crystal grains [3]. When the metal is deformed by cold drawing, dislocation and other imperfections such as vacancies are introduced into the crystal structure generating microstructure heterogeneities that exhibit large orientation gradient [4]. The grains then acquire a preferred orientation or texture. The structural changes which occur include the gradual stretching of the grains in the direction of principal de- formation and accumulation of dislocation and some other defects [5]. The accumulation and migration of the dislocation due to the cold drawing process results in strain hardening of the steel allowing for increase in its tensile strength with reduced ductility [6]. The degree of cold-drawn deformation determines whether the steel will attain a brittle nature or remains ductile [7]. The strain hardening also known as work hardening is an increment in internal energy associated with an increase in the dislocation density as well as density in point defects, such as vacancies and interstitials $[8,9]$. Some other effects of such cold work on the properties of polycrystalline structures have been studied extensively [10-20]. The individual grain of a polycrystalline material changes relative to the direction of applied stress during the deformation which is distributed heterogeneously among the individual grains [21]. A typical feature of such deformed structure is anisotropy of mechanical properties. An initially isotropic material responds by developing anisotropy when subjected to inelastic deformation. The 
inelastic induced anisotropy includes directional anisotropy in cold worked metals [22]. These changes in the mechanical properties of the steel due to the deformation often influence the performance of the resulting product of the process in service. In the case of wire drawing process for plain nail manufacture, the steel is cold-drawn to sizes at $20 \%, 25 \%, 40 \%$, and $55 \%$ for the manufacture of 4 inches, 3 inches, 2.5 inches and 2 inches respectively. During the drawing operation the carbon steel experiences microstructure changes which affect the mechanical properties of the steel and consequently the performance of the resulting product in service [23]. The associated problems include high strain hardening of the steel due to the degree of plastic deformation which causes nail brittleness or poor ductility resulting in buckling of the nail in service. The large amount of internal strain in the form dislocation as a result of the strain hardening means that energy is stored in the metal. This energy can be released through heat treatment, where energy in the form of heat is introduced into the material allowing the release of stored energy in the process of recrystallization [24]. Recrystallization is the reconstruction of the grain structure during annealing of deformed metals. It causes a change in the grain structure of the material that has been previously cold-worked or plastically deformed. The recrystallization process tends to eliminate the dislocations by means of migration of high-angle grain boundaries driven by the stored energy of deformation and a new grain structure in the deformed material evolved. $[25,26]$. Thus, new dislocation-free grains are formed within the recovered structure. The new grains then grow at the expense of the old deformed grains, leaving a new structure with low dislocation. The new structure consumes the old grains, resulting in a new grain structure with a very or no low dislocation density [27].

Recrystallization is a function of the amount of strain induced during deformation as well as the time and temperature of annealing [28]. In this study, the recrystallization kinetics and the corresponding microstructure evolution in annealed cold-drawn low carbon steel is investigated according to annealing time by mechanical test and microstructure characterization. The kinetics of recrystallization involves determining the fraction of recrystallized grains with annealing time which is used to describe the evolution of the recrystallized grains with increasing time of annealing at a particular temperature [29]. The studies of the recrystallization kinetics have shown that the mechanical properties of metallic materials could be controlled by the microstructure of the material $[28,30,31]$. The control of the microstructure of the steel could therefore be used to obtain desired mechaniccal properties for the steel. The idea of control of mechanical properties in materials through these processing techniques has been studied [32].

Recrystallization is a thermally activated process, consisting of the generation of strain-free grains and their growth at the expense of the deformed grains until the deform grain is entirely consumed [28]. And the driving force for recrystallization is the energy stored in the material during deformation [33]. The purpose of recrystallization is to refine the grains for improved properties and important mechanical properties can be restored after annealing of cold deformed steel allowing for further deformation.

The generally accepted empirical model used to describe recrystallization kinetics is the Johnson-Mehl-Avrami-Kolmogorov (JMAK) expressed [28,30,33] as:

$$
X_{v}=1-\exp \left[-k t^{n}\right]
$$

where $X_{v}$ the volume recrystallized, $k$ is the JMAK variable which is temperature dependent and $n$ is the JMAK exponent and $t$ is the annealing time.

The model was developed on the assumption that the recrystallized nuclei form randomly in the cold-worked microstructure and that the growth of the nuclei is isotropic but real materials do not exhibit this behavior because of the non-uniform distribution of the stored energy, non-random distribution of the nuclei and anisotropic growth of recrystallized nuclei [34]. It is therefore of importance to consider real situation of the recrystallization process through experimentation as input for a realistic model.

This paper considered the use of the micro hardness property of the annealed cold drawn low carbon steel at different temperature and soaking time to investigate the recrystallization process for desired mechanical properties.

\section{Materials and Methods}

The low carbon steel used for this study is obtained from Nigeria Wire Industry Ltd, Ikeja, Nigeria. The average chemical composition for the steel is as given in Table 1. Samples of wire cold-drawn by $25 \%$ and $40 \%$ degree of deformation were obtained. A Muffle furnace, Gallenkomp $^{\circledR}$ model SVL-1009 with voltage regulation of 220 $\mathrm{V}, 50 \mathrm{~Hz}$ of temperature range $300^{\circ} \mathrm{C} \sim 1000^{\circ} \mathrm{C}$ obtained in the materials test laboratory of Igbinedion University, Okada was used to annealed the steel at $650^{\circ} \mathrm{C}$ and $700^{\circ} \mathrm{C}$ for time interval ranging from 5 minutes to 60 minutes.

Table 1. Chemical composition of the as-received steel wire material (wt\%).

\begin{tabular}{ccccc}
\hline $\mathrm{C}$ & $\mathrm{Si}$ & $\mathrm{Mn}$ & $\mathrm{P}$ & $\mathrm{Fe}$ \\
\hline 0.12 & 0.18 & 0.14 & 0.7 & 98.86 \\
\hline
\end{tabular}


The samples for evaluation of the microstructures by optical microscopy (OM) were cut from the annealed wire, and taken through a grinding process on silicon carbide paper, 240, 320, 400, and 600 grit. The samples were then polished initially at $1 \mu \mathrm{m}$ and finally at $0.5 \mu \mathrm{m}$ using emery cloth and silicon carbide solution, etched with $2 \%$ nital and the metallography was carried out using the optical microscope (OM) with image capturing device. The hardness test was done on a Brinnel tester. In preparation for hardness measurements, scaling on the surface of each of the annealed specimens was removed in the area where the test was to be conducted. A wire brush was used to remove the surface scaling. Each specimen for the hardness test was filed to create flat surface on the nail shank. The flat surface was then polished with emery paper to obtain very smooth surface required of the test. The Brinnell test for this experiment employed a 1-mm diameter carbide ball which was pressed onto the specimen by a $1750-\mathrm{g}$ load that was maintained for 10 seconds. The diameter of the indenter impression was measured with the Brinnel reading microscope of magnification $20 \times$ and the measurement converted to the Brinell-Hardness Number on the Brinnel tester conversion table.

The recrystallization fraction is determined based on the hardness measurement using Expression (1) [33].

$$
X_{v}=\frac{\mathrm{BHN}_{\text {initial }}-\mathrm{BHN}(\mathrm{t})}{\mathrm{BHN}_{\text {initial }}-\mathrm{BHN}_{\text {final }}}
$$

where $\mathrm{BHN}_{\text {initial }}$ the hardness of the deformed sample, $\mathrm{BHN}_{\text {final }}$ is the hardness of the fully recrystallized sample and $\operatorname{BHN}(\mathrm{t})$ is the hardness after a given soaking time.

\section{Results and Discussion}

\subsection{Microstructure Evolution}

Figures 1(a)-(f) show the microstructure evolution of the $25 \%$ cold-drawn low-carbon steel and as annealed at $650^{\circ} \mathrm{C}$ for annealing time range of $5-20$ minutes. The microstructure of the cold-drawn steel shown in Figure 1(a) non-treated is inhomogeneous with accumulating dislocation density concentrated at the grain boundaries as indicated by the large area of dark patterns of the structure. After annealing the drawn steel at $650^{\circ} \mathrm{C}$ for a soaking time of $5-10$ minutes, annihilation of the dislocation is observed with most of the dark patterns clearing off the structure. Specifically at 5 minutes soaking time as shown in Figure 1(b), the grains elongation is still observed indicating that reformation of grains is not taking place but recovery of the deformed grains which involves movement of low-angle grain boundaries. At the 10 minutes annealing time, new grains are observed to begin to form as shown in Figure 1(c) and full recrystallization is achieved at 15 minutes annealing time as shown in Figure 1(d). At annealing time between 20 - 25 minutes, grains coarsening are observed indicating the onset of grain growth. This is usually avoided in-order to keep the required strength of the material.

\subsection{Material Hardness}

Figures 2-5 show the steel hardness measured from the Brinnel hardness test as a function of the soaking time at different annealing temperature for the $20 \%, 25 \%, 40 \%$ and $55 \%$ cold drawn steel respectively. It is observed that recrystallization could be said to start after 600 seconds at all the applied annealing temperatures. The hardness of
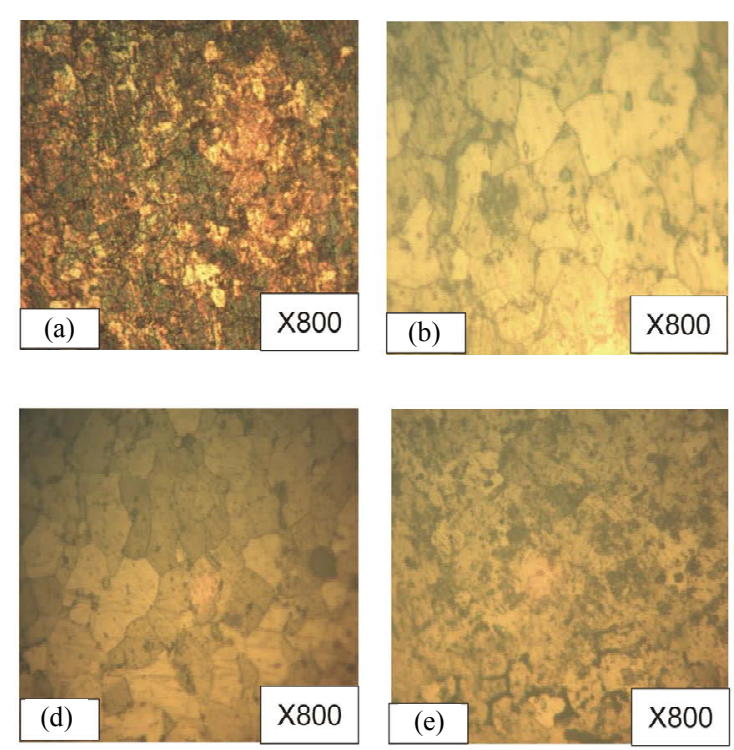

Figure 1. (a) As-received cold-drawn at 25\%; (b) annealing time of $5 \mathrm{~min}$; (c) annealing time of $10 \mathrm{~min}$; (d) annealing time of $15 \mathrm{~min}$; (e) annealing time of $20 \mathrm{~min}$; (f) annealing time of $25 \mathrm{~min}$. 


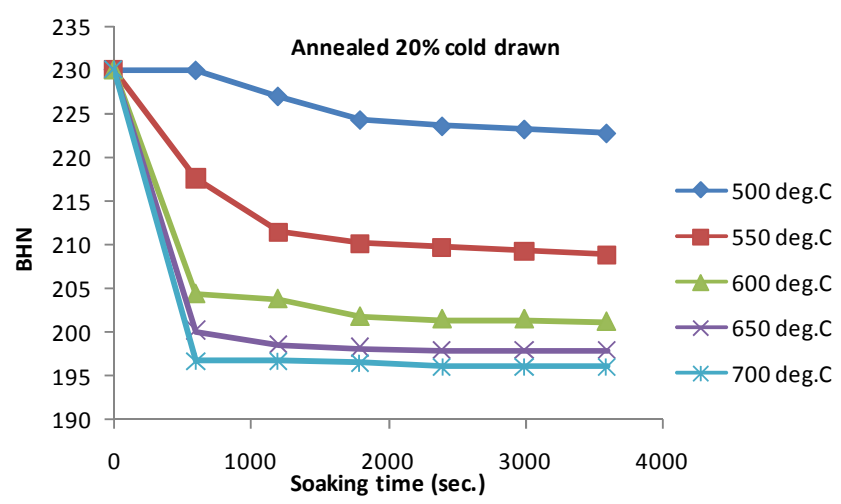

Figure 2. Influence of soaking time on hardness of annealed $20 \%$ cold drawn $0.12 \mathrm{wt} \% \mathrm{C}$ steel.

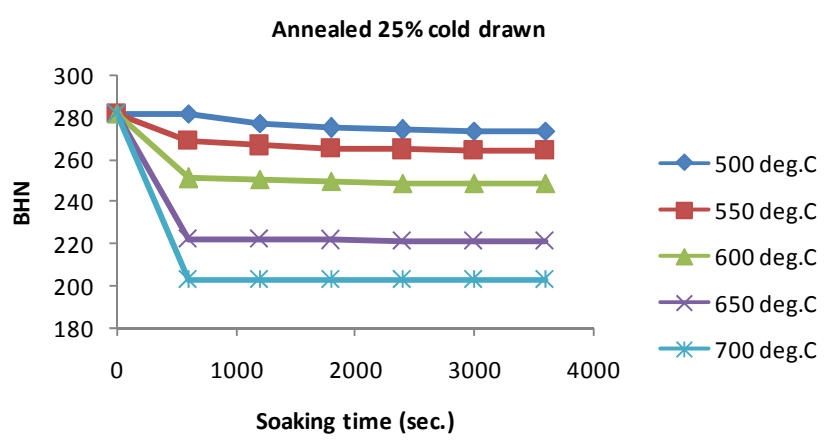

Figure 3. Influence of soaking time on hardness of annealed $25 \%$ cold drawn $0.12 \mathrm{wt} \% \mathrm{C}$ steel.

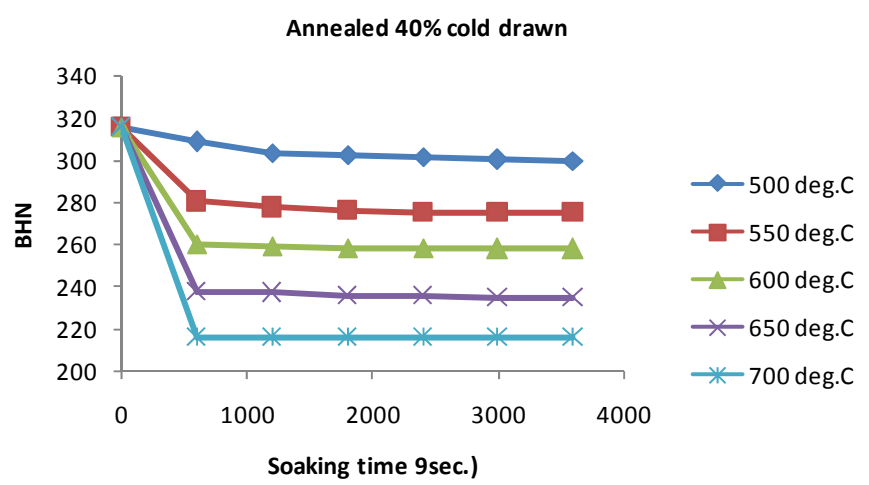

Figure 4. Influence of soaking time on hardness of annealed $40 \%$ cold drawn $0.12 \mathrm{wt} \% \mathrm{C}$ steel.

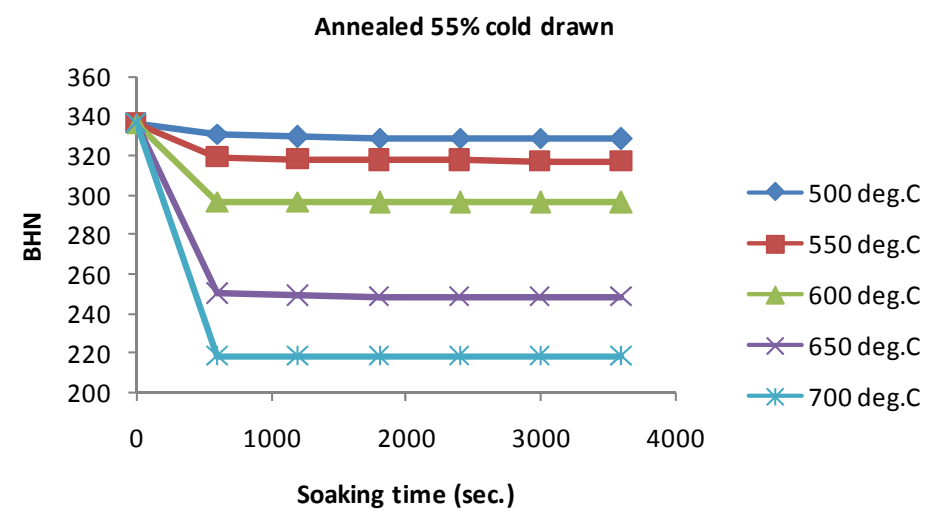

Figure 5. Influence of soaking time on hardness of annealed $55 \%$ cold drawn $0.12 \mathrm{wt} \% \mathrm{C}$ steel. 
the material reduces with increasing annealing temperature for all the degree of cold deformation. This implies that rate of recrystallization increases with increasing annealing temperature.

\subsection{Recrystallization Kinetics}

The evolution of the recrystallization was measured by the Brinnel hardness during the annealing at $600^{\circ} \mathrm{C}$ and $650^{\circ} \mathrm{C}$. Table 2 shows the hardness values of the steel.

The maximum and minimum hardness values were measured from the hardness test such that the maximum hardness correspond to the hardness of the material at time of zero seconds which is the hardness of the deformed material without annealing and the minimum hardness correspond to the hardness of the fully recrystallized grain.

The relationship between the recrystallization kinetics and soaking time showing the influence of the degree of cold drawn deformation are shown in Figures $\mathbf{6}$ and $\mathbf{7}$ for the $20 \%, 25 \%, 40 \%$ and $55 \%$ degree of cold drawing annealed at temperatures of $600^{\circ} \mathrm{C}$ and $650^{\circ} \mathrm{C}$. The figures show truncated sigmoidal shape lacking the small slope region which usually describe the nucleation period of recrystallization. This could be explain that the lack of the clear nucleation region of the curves is as a result of prolonging recovery process which tends to reduce the driving force required for nucleation at lower soaking time. The extent of recovery decreases with increasing degree of cold drawn deformation. The prolonged recovery process in the $20 \%$ and $25 \%$ cold drawn steel could be as a result of reduction in the driving force required for nucleation at lower soaking time. It is also observed that the rate of recrystallization increases with increasing degree of cold drawn deformation. This means that recovery process is faster in the highly cold drawn steel. The influence of recovery is to cause the recrystallizing grain growth rate to decrease continuously during recrystallization. The figures show that full recrystallization of the grains commenced at different soaking time for the cold drawn steel depending on the degree of cold drawn deformation.

\section{Conclusion}

The microstructure evolution of cold drawn $0.12 \mathrm{wt} \% \mathrm{C}$ steel has been analyzed. The accumulated dislocation due to cold drawing deformation of the steel annihilate after annealing the drawn steel at $650^{\circ} \mathrm{C}$ for a soaking time of 5 - 10 minutes, annihilation of the dislocation is observed with most of the dark patterns clearing off the structure. At lower soaking time, recovery of the deformed grains is pronounced. Recrystallization of the grains commenced after annealing for soaking time of 10 minutes. At annealing time between 20 - 25 minutes, grains coarsening are observed indicating the onset of grain growth. The hardness of the material reduces with increasing annealing temperature for all the degree of cold deformation indicating increasing recrystallization with increaseing annealing temperature. The kinetics of recrystallization has been described with the hardness test values for cold drawn $0.12 \mathrm{wt} \% \mathrm{C}$ steel annealed at $600^{\circ} \mathrm{C}$ and

Table 2. Initial and recrystallized values for hardness of cold drawn $0.12 \mathrm{wt} \% \mathrm{C}$ steel.

\begin{tabular}{cccc}
\hline $\begin{array}{c}\% \\
\text { Deformation }\end{array}$ & $\mathrm{BHN}_{\text {initial }}$ & $\begin{array}{c}\mathrm{BHN}_{\text {final }} \\
\left(\text { annealed at } 600^{\circ} \mathrm{C}\right)\end{array}$ & $\begin{array}{c}\mathrm{BHN}_{\text {final }} \\
\left(\text { annealed at } 650^{\circ} \mathrm{C}\right)\end{array}$ \\
\hline 20 & 230 & 201.2 & 197.91 \\
25 & 281.65 & 248.3 & 221 \\
40 & 315.67 & 257.7 & 234.6 \\
55 & 336 & 296 & 248 \\
\hline
\end{tabular}

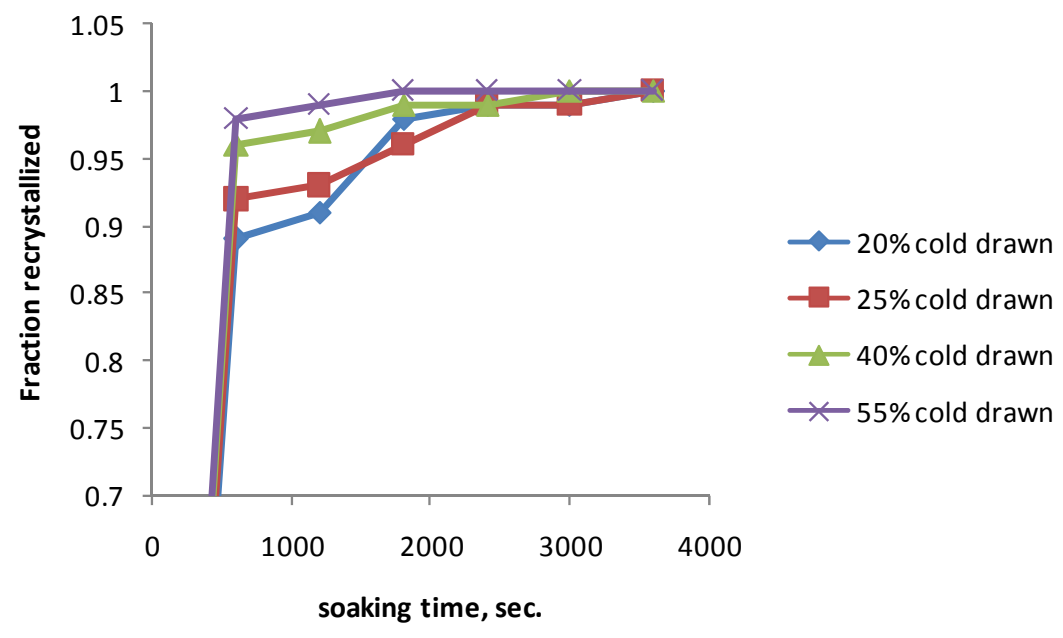

Figure 6. Recrystallization kinetics of cold drawn $0.12 \mathrm{wt} \% \mathrm{C}$ steel annealed at $600 \mathrm{deg}$. C. 


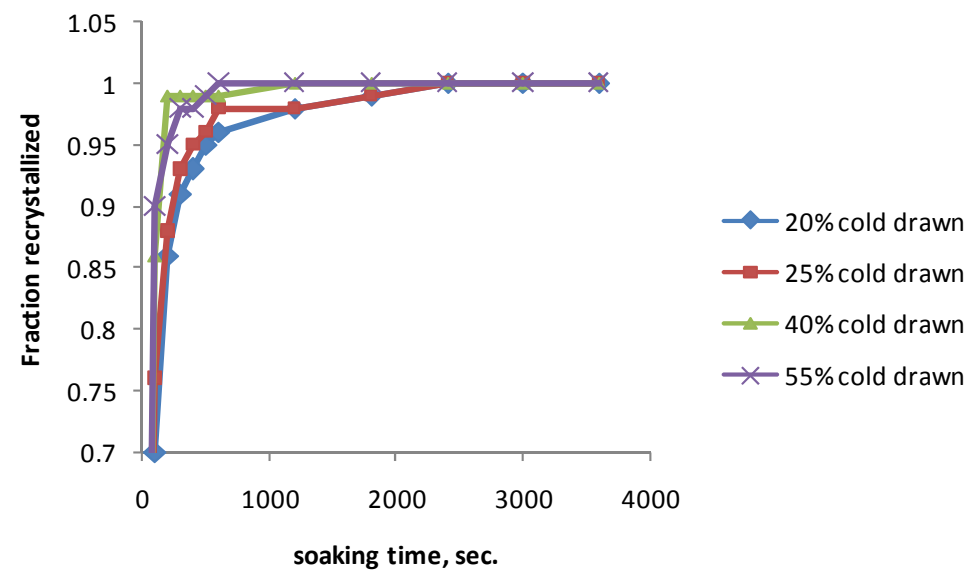

Figure 7. Recrystallization kinetics of cold drawn 0.12 wt \% C steel annealed at 650 deg. C.

$650^{\circ} \mathrm{C}$. The recrystallization kinetic is characterized by prolonged recovery at lower soaking time and rate of recrystallization increases with increasing degree of cold drawn deformation. Full recrystallization is achieved faster in the highly deformed steel.

\section{REFERENCES}

[1] E. N. Popova, V. V. Popov, E. P. Romanov, N. E. Hlebova and A. K. Shikov, "Effect of Deformation and Annealing on Texture Parametal of Composite $\mathrm{Cu}-\mathrm{Nb}$ Wire," Scupta Materialia, Vol. 51, No. 7, 2004, pp. 727-731. http://dx.doi.org/10.1016/j.scriptamat.2004.05.037

[2] F. Yan, C. Ma, J. Q. Jiang, H. P. Feng and S. T. Zha, "Effect of Cumulative Strain on Texture Characteristics during Wire Drawing of Eutectoid Steels," Scripta Materialia, Vol. 59, No. 8, 2008, pp. 850-853. http://dx.doi.org/10.1016/j.scriptamat.2008.06.048

[3] F. J. Humphreys and M. Hatherly, "Recrystallization and Related Annealing Phenomena," 2nd Edition, Elsevier Ltd., Amsterdam, 2004.

[4] M. Ferry, "Influence of Fine Particle of Grain Coarsening within an Orientation Gradient," Acta Materialia, Vol. 53, No. 3, 2005, pp. 773-783. http://dx.doi.org/10.1016/j.actamat.2004.10.030

[5] J. Schindler, M. Janošec, E. Místecky, M. Rǔžička, L. A. Č́žzek Dobrzdviski, S. Rusz and P. Svenanek, "Effect of Cold Rolling and Annealing on Mechanical Properties of HSLA Steel," Achives of Materials Science and Engineering, Vol. 36, No. 1, 2009, pp. 41-47.

[6] A. Phelippeau, S. Pommier, T. Tsakalakos and M. P. C. Clavel, "Cold Drawn Steel Wires-Processing, Residual Stresses and Ductility_Part I: Metallography and Finite Element Analyses," Fatigue Fracture Engineering Material Structure, Vol. 29, No. 3, 2006, pp. 243-253. http://dx.doi.org/10.1111/j.1460-2695.2005.00981.x

[7] N. A. Raji and O. O. Oluwole, "Influence of Degree of Cold-Drawing on the Mechanical Properties of Low Carbon Steel," Materials Sciences and Applications, Vol. 2, No. 11, 2011, pp. 1556-1563. http://dx.doi.org/10.4236/msa.2011.211208
[8] A. L. R. de Castro, H. B. Campos and P. R. Cetlin, "Influence of Die Semi-Angle on Mechanical Properties of Single and Multiple Pass Drawn Copper," Journal of Materials Process and Technology, Vol. 60, No. 1-4, 1996, pp. 179-182. http://dx.doi.org/10.1016/0924-0136(96)02325-4

[9] D. G. Cram, H. S. Zurob, Y. J. M. Brechet and C. R. Hutchinsm, "Modeling Discontinuous Dynamic Recrystallization Using a Physically Based Model for Nucleation," Acta Materialia, Vol. 57, No. 17, 2009, pp. 52185228. http://dx.doi.org/10.1016/j.actamat.2009.07.024

[10] J. A. Wert, Q. Liu and N. Hansen, "Dislocation Boundary Formation in Cold-Rolled Cube-Orientation Al Single Crystal," Acta Materialia, Vol. 45, No. 6, 1997, pp. 25652576. http://dx.doi.org/10.1016/S1359-6454(96)00348-5

[11] C. Maurice and J. H. Driver, "Hot Rolling Texture of F.C.C. Metals-Part 1. Experimental Results on Al Sample and Polycrystals," Acta Materialia, Vol. 45, No. 11, 1997, pp. 4627-4638. http://dx.doi.org/10.1016/S1359-6454(97)00115-8

[12] A. Godfrey, D. J. Jensen and N. Hansen, "Recrystallization of Channel Die Deformed Single Crystals of Typical Rolling Orientation," Acta Materialia, Vol. 49, No. 13, 2001, pp. 2429-2440. http://dx.doi.org/10.1016/S1359-6454(01)00148-3

[13] N. Hansen and X. Huang, "Microstructure and Flow Stress of Polycrystals and Single Crystals," Acta Materialia, Vol. 46, No. 5, 1998, pp. 1827-1836. http://dx.doi.org/10.1016/S1359-6454(97)00365-0

[14] F. Bossom and J. H. Driver, "Deformation Banding Mechanisms during Plain Strain Compression of Cube Oriented F.C.C. Crystals," Acta Materialia, Vol. 48, No. 9, 2000, pp. 2101-2115. http://dx.doi.org/10.1016/S1359-6454(00)00042-2

[15] S. Zaefferer, J. C. Kuo, Z. Zhao, M. Winning and D. Raabe, "On the Influence of the Grain Boundary Misorientation on the Plastic Deformation of Aluminum Bicrystals," Acta Materialia, Vol. 51, No. 16, 2003, pp. 47194735. http://dx.doi.org/10.1016/S1359-6454(03)00259-3

[16] S. Ganapathysubramanian and N. Zabaras, "Deformation Process Design for Control of Microstructure in the 
Presence of Dynamic Recrystallization and Grain Growth Mechanisms," International Journal of Solids and Structures, Vol. 41, No. 7, 2004, pp. 2011-2037. http://dx.doi.org/10.1016/j.ijsolstr.2003.11.020

[17] G. V. S. S. Prasad, M. Goerdeler and G. Gottstein, "Work Hardening Model Based on Multiple Dislocation Densities," Material Science and Engineering A, Vol. 400-401, 2005, pp. 231-233. http://dx.doi.org/10.1016/i.msea.2005.03.061

[18] M. Dománková, M. Peter and M. Roman, "The Effect of Cold Work on the Sensitization of Austenitic Stainless Steels," Materiali in Technologije, Vol. 41, No. 3, 2007, pp. 131-134.

[19] Z. Huda, "Effect of Cold Working and Recrystallization on the Mecristructure and Hardness of Commercial-Purity Aluminum," European Journal of Scientific Research, Vol. 26, No. 4, 2009, pp. 549-557.

[20] S. J. Pawlak and H. J. Krzton, "Cold Worked High Alloy Ultra-High Strength Steels with Aged Matensite Structure," Journal of Achievement in Materials and Engineering, Vol. 36, No. 1, 2009, pp. 18-24.

[21] J. J. Sidor, R. H. Petrov and L. A. I. Kestens, "Microstructure and Texture Changes in Severely Deformed Aluminum Alloys," Material Characterization, Vol. 62, No. 2, 2011, pp. 228-236. http://dx.doi.org/10.1016/j.matchar.2010.12.004

[22] T. Fuller and R. M. Brannon, "On the Thermodynamic Requirement of Elastic Stiffness Anisotropy in Isotropic Materials," International Journal of Engineering Science, Vol. 49, No. 4, 2011, pp. 311-321 http://dx.doi.org/10.1016/j.ijengsci.2010.12.017

[23] N. A. Raji and O. O. Oluwole, "Effect of Cold Drawn Deformation on Mechanical Properties of Low-Carbon Steel Due to Changes in Grain Sizes," Nigerian Society of Engineers Technical Transactions, Vol. 46, No. 3, 2011, pp. 69-78.

[24] M. Janošec, I. Schindler, V. Vodárek, J. Palát, S. Rusz, P. Suchánek, M. Růžička, E. Místecký and N. Hut', "Microstructure and Mechanical Properties of Cold Rolled, Annealed HSLA Strip Steels," Archives of Civil and Mechanical Engineering, Vol. 7, No. 2, 2007, pp. 29-38.

[25] P. R. Rios, F. Siciliano, R. Z. Sandim, R. L. Plant and A. F. Padilha, "Nucleation and Growth during Recrystalliza- tion," Material Research, Vol. 8, No. 3, 2005, pp. 225238. http://dx.doi.org/10.1590/S1516-14392005000300002

[26] R. A. Vandermeer and D. T. Juul Jensen, "Microstructural Path and Temperature Dependence of Recrystallization in Commercial Aluminum," Acta Materialia, Vol. 49, No. 11, 2001, pp. 2083-2094. http://dx.doi.org/10.1016/S1359-6454(01)00074-X

[27] R. D. Doherty, "Recrystallization and Texture," Progress in Material Science, Vol. 42, No. 1-4, 1997, pp. 39-58. http://dx.doi.org/10.1016/S0079-6425(97)00007-8

[28] H. Hallberg, "Approaches to Modeling of Recrystallization," Metals, Vol. 1, No. 1, 2011, pp. 16-48. http://dx.doi.org/10.3390/met1010016

[29] S. P. Chen, D. N. Hanlon and S. Van der Zwaag, "Quantification of the Recrystallization Behavior in Al-Allo AA 1050," Journal of Material Sciences, Vol. 37, No. 5, 2002, pp. 989-995. http://dx.doi.org/10.1023/A:1014356116058

[30] P. N. Kalu and D. R. Waryoba, “A JMAK-Microhardness Model for Quantifying the Kinetics of Restoration Mechanisms in Inhomogeneous Microstructure," Materials Science and Engineering A, Vol. 464, No. 1-2, 2007, pp. 6875. http://dx.doi.org/10.1016/j.msea.2007.01.124

[31] D. P. Field, L. T. Bradford, M. M. Nowell and T. M. Lillo, "The Role of Annealing Twins during Recrystallization of Cu," Acta Materialia, Vol. 55, No. 12, 2007, pp. 42334241. http://dx.doi.org/10.1016/j.actamat.2007.03.021

[32] R. L. Goetz and V. Seethenaman, "Modeling Dynamic Recrystallization Using Cellular Automata," Scripta Materialia, Vol. 38, No. 3, 1998, pp. 405-413. http://dx.doi.org/10.1016/S1359-6462(97)00500-9

[33] Y. Lü, D. A. Molodov and G. Gottstein, "Recrystallization Kinetics and Microstructure Evolution during Annealing of a Cold-Rolled Fe-Mn-C alloy," Acta Materialia, Vol. 59, No. 8, pp. 3229-3243. http://dx.doi.org/10.1016/j.actamat.2011.01.063

[34] B. Radhakrishnan, G. B. Sarma and T. Zacharia, "Modeling the Kinetics and Microstructure Evolution during Static Recrystallization-Monte Carlo Simulation of Recrystallization," Acta Materialia, Vol. 46, No. 12, 1998, pp. 4415-4433.

http://dx.doi.org/10.1016/S1359-6454(98)00077-9 